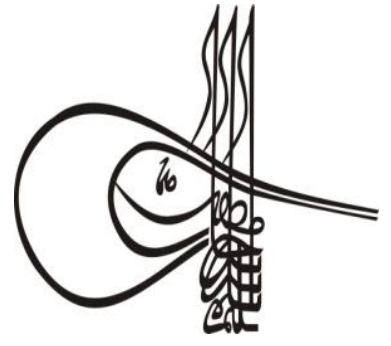

Received/Geliş: 21.06.2019

\section{Turkígh Gtudies \\ Social Sciences}

Volume 14 Issue 4, 2019, p. 1277-1287

DOI: 10.29228/TurkishStudies.23418

ISSN: 2667-5617

Skopje/MACEDONIA-Ankara/TURKEY

Research Article / Araştırma Makalesi

Article Info/Makale Bilgisi

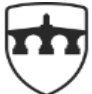

INTERNATIONAL BALKAN UNIVERSITY

EXCELLENCE FOR THE FUTURE IBU.EDU.MK

Gor Report Dates/Rapor Tarihleri: Referee 1 (11.07.2019)-Referee 2 (16.07.2019)

This article was checked by turnitin.

\title{
TÜRKIYY'DE TARIM VE GIDA SEKTÖRÜNÜN REKABET GÜCÜNÜN ÖLÇÜMÜ
}

\author{
Ali BERK*
}

öz

Tarım sektörü sadece ülkelerin beslenmesi açısından önemli olmayıp, dış ticarete konu olması yönüyle de stratejik özellik taşımaktadır. Bu yönüyle de tarım sektörü uluslararası ilişkilerin vazgeçilmez bir parçasını oluşturmaktadır. Küresel düzeyde DTÖ politikalarının etkisiyle de küresel ticaret serbestleşmeye devam etmektedir. 1980 yılında 2 trilyon \$ seviyesinde olan toplam küresel ihracat hacmi, 2017 sonunda 17,7 trilyon \$'1 assmıştır. Türkiye'de ise 2002 yllinda 36,1 Milyar \$ olan ihracat 2018 itibariyle 167,9 Milyar \$'a, aynı dönemde tarımsal ürünler ihracatı ise 4,1 Milyar \$'dan \%356,5 oranında artışla 18,5 Milyar \$’a yükselmiştir.

$\mathrm{Bu}$ çalışmada, Türkiye'nin tarım ve gıda sektörünün rekabet gücünün 1990-2018 dönemine ait endüstri içi diş ticaret değerleri dikkate alınarak ölçümü amaçlanmıştır. Analiz sonuçlarına göre toplam tarım ürünleri dış ticaretinde 28 yıllık dönemde endüstri içi ticaret değeri ortalaması 0,92 iken, bu değer gida maddelerinde 0,72 olarak tespit edilmiştir. Türkiye'nin tarım ve gıda ürünleri diş ticaretinde yüksek endüstri-içi ticaret avantajına sahip ve gelecek açısından potansiyeli bulunan bir ülke olduğu söylenebilir.

Bununla birlikte rekabette var olan karş1laştırmalı rekabet avantajının korunması ve rekabet gücünün arttırılmasında; maliyetlerin azaltılması, yerel ve coğrafi işaret gibi araçlar yoluyla markalaşmanın arttırılması, kayıtdışı ile mücadele, dış ticarette pazar çeşitlendirmesi, katma değeri yüksek ürünlerin üretilmesi ve dijital tarıma geçiş süreçlerine yatırım yapılması önemli rol oynayacaktır.

Anahtar Kelimeler: Rekabet, Endüstri İçi Ticaret, Tarım ve Gıda, Grubel-Lloyd Endeksi 


\title{
MEASUREMENT OF COMPETITIVENESS OF AGRICULTURE AND FOOD SECTOR IN TURKEY
}

\begin{abstract}
The agricultural sector is not only important in terms of the nutrition of the countries but also has a strategic feature in terms of being subject to foreign trade. In this respect, the agricultural sector is an essential part of international relations. Global trade continues to liberalize under the influence of WTO policies at global level. The total global export volume, which was 2 trillion $\$$ in 1980 , exceeded 17.7 trillion $\$$ at the end of 2017. In the same time, the export volume in Turkey is increased 36.1 billion $\$$ to 167.9 billion $\$$ between the in period of 2002-2018, while during the same period, exports of agricultural products increased from 4.1 billion $\$$ to 18.5 billion $\$$ by increasing as $356.5 \%$.

The aim of this study is to measure the competitiveness of the intra-industry trade, foreign trade of agriculture and food sector of Turkey for the period of 1990-2018. According to the results of the analysis, while the average value of intra-industry trade in the total trade of agricultural products in the 28 -year period was 0.92 , this value was determined as 0.72 in food items. Turkey is a country with high intra-industry trade advantage in agricultural and food products and it has a potential for the future.

However, to maintain the competitive advantage and increasing competitiveness; reducing costs, increasing branding through local and geographical indicators, struggling with the informal economy, market diversification in foreign trade, producing high value-added products and investing to digital agriculture will have an important role.
\end{abstract}

\section{STRUCTURED ABSTRACT}

The agricultural sector is not only important for the nutrition of the countries but also has a strategic characteristic in terms of being subject to foreign trade. As a matter of fact, food crises and price increases experienced with the globalization adversely affect countries. In this respect, the agricultural sector is an integral part of international relations and agreements. The studies as intra-industry trade in the agricultural and food sector which are getting important day by day in developing countries is getting popular in the competitiveness studies. In the literature studies, the concentration of foreign trade in sectors where similar goods are produced is called de intra-industry whereas the concentration of foreign trade among different industries is called inter-industry trade.

The agricultural sector is not only important in terms of the nutrition of the countries but also has a strategic feature in terms of being subject to foreign trade. In this respect, the agricultural sector is an essential part of international relations. Global trade continues to liberalize under the influence of WTO policies at global level. The total global export volume, which was 2 trillion $\$$ in 1980 , exceeded 17.7 trillion $\$$ at the end of 2017 . In the same time, the export volume in 
Turkey is increased 36.1 billion $\$$ to 167.9 billion $\$$ between the in period of 2002-2018, while during the same period, exports of agricultural products increased from 4.1 billion $\$$ to 18.5 billion $\$$ by increasing as $356.5 \%$.

The agricultural sector in Turkey has an experience the process of outward-oriented and export-led growth in the agricultural sector "intra-industry trade" as another factor in the growing weight as a work to do to win the competition emerges.

The data used in this study are provided from TurkStat database and are based on Standard International Trade Classification (SITC, Rev.3). The period of 1990-2018 consists of annual export and import figures. This study mainly targets to analysis in the agricultural sector, food from the sub-sector, livestock and food products, beverages, tobacco and tobacco products in Turkey by using Grubel-Lloyd method for animal and vegetable fats and products with intra-industry trade of agricultural raw materials. However, total agricultural sector which is the main sub-sectors subject to Turkey ECO measuring trade in agriculture to determine the role of ECO are also among the study objectives.

The aim of this study is to measure the competitiveness of the intra-industry trade, foreign trade of agriculture and food sector of Turkey for the period of 1990-2018. According to the results of the analysis, while the average value of intra-industry trade in the total trade of agricultural products in the 28 -year period was 0.92 , this value was determined as 0.72 in food items. Turkey is a country with high intra-industry trade advantage in agricultural and food products and it has a potential for the future.

For more detail, milk, dairy products and eggs, cereals, cereals products, coffee, tea, cocoa, spices and products and various edible products (oil, homogenized products, sauce, yeast, etc.), while the high level of intra-industry trade in sub-sectors live animals, meat and meat products, fish and other seafood, fruits and vegetables, sugar, sugar products and honey, foodstuffs for animals, beverages, animal fats and oils, vegetable oils and friction, oilseeds, oil-bearing fruits and unprocessed leather, leather and fur, raw rubber, mushrooms, wood and timber, pulp and used paper and woven fibers and their residues.

According to results of this study, Turkey's agricultural and food products in foreign trade with the advantage of high intra-trade industry and despite the existence of potential, said to be associated with protection rates applied in foreign trade. In addition, Turkey's trade in agricultural and processed agricultural products are both exporters and importers, and this one seems to be effective in protection measures. Furthermore, in the process of updating the Customs Union with the EU, inclusion of the agricultural sector and liberalization may create significant competitive pressure on various products. In this context, Turkey's agriculture and effective and efficient use of natural resources, reduction of input costs, lowering prices for consumers are among the items that will enhance the competitiveness of prevention. As a result, Turkey, agricultural liberalization process will occur according to the new conditions in order to adapt to the competitive environment, it is necessary to develop new policies and strategies.

\section{Turkish Studies - Social Sciences}

Volume 14 Issue 4, 2019 
However, to maintain the competitive advantage and increasing competitiveness; reducing costs, increasing branding through local and geographical indicators, struggling with the informal economy, market diversification in foreign trade, producing high value-added products and investing to digital agriculture will have an important role.

Keywords: Competition, Intra-Industry Trade, Agriculture and Food, Grubel-Lloyd Index

\section{Giriş}

Günümüzde küresel ölçekte uluslararası alanda yaşanan serbestleşme, ülkelerarası karşıllıklı hızlı etkileşim, entegrasyon ve teknolojik gelişmeler ile ekonomik, sosyal, kültürel ve ticari ilişkilerin kapsamı geniş̧lemiştir. Yaşanan bu süreç, uluslararası ticaretin güvence altına alınması amacıyla 1947'de Gümrük Tarifeleri ve Ticaret Genel Anlaşması (GATT) ile başlamış, Uluslararası Para Fonu (IMF) ve Dünya Bankası kurulmasının ardından, Dünya Ticaret Örgütü (DTÖ)'nün kurulmasıyla devam etmiştir.

Diğer yandan da Avrupa Topluluğu'nun Avrupa Birliği’ne dönüşmesi, ortak para birimi Euro'nun kabul edilmesi (1999), küresel ticaretin serbestleştirilmesi yönünde kapsamlı son adım olan Uruguay Turu'nun tamamlanması (1994), Dünya Ticaret Örgütü'nün (DTÖ) kurulması (1995), Çin Halk Cumhuriyeti'nin DTÖ üyesi olması (2001) gibi gelişmeler küresel ticaret rejimini şekillendiren önemli gelişmeler arasında sayılabilir. Gelişmiş sanayi ülkeleri, bu dönemde, Uluslararası Para Fonu (IMF), Dünya Bankası ve GATT/Dünya Ticaret Örgütünün oluşturduğu sistemde başat güç olarak etkinlik sağlamıştır. Bu sistemin sağladığı istikrar, liberalleşme savlarının genel kabul görmesine yol açmıştır (GIF, 2018).

Tarım sektörü sadece ülkelerin beslenmesi açısından önemli olmayıp, dış ticarete konu olması yönüyle de stratejik özellik taşımaktadır. Nitekim küreselleşmeyle birlikte, yaşanan gıda krizleri ve fiyat artışları ülkeleri olumsuz olarak etkimektedir. Bu yönüyle de tarım sektörü uluslararası ilişkiler ve anlaşmaların da ayrılmaz bir parçasını oluşturmaktadır.

Bu kapsamda uluslararası genel ve tarım ticaretini düzenleyen etkili mekanizmaların başında DTÖ gelmektedir. Söz konusu DTÖ anlaşmaları içerisinde yer alan Tarım Anlaşmasının (Ek 1A-2) 20. maddesine göre; üye ülkelerin anlaşmayı, ticaretin serbestleştirilmesi yönünde sürekli olarak tadil etme yönünde müzakerelere açı olacağı hükmü nedeniyle, 1947'den bugüne kadar turlar şeklinde devam eden 8 adet müzakere turu yapılmıştır. 9. Müzakere turu ise 2000 yılında Doha Bakanlar Konferansı ile başlatılan Doha Müzakere Turu olup günümüze kadar devam etmiş ve halen de devam etmektedir.

2005 y1lındaki Hong Kong Bakanlar Konferansı'nda, 2006 y1lında tamamlanmas1 amaçlanmasına rağmen, 2006 Temmuz ayında askıya alınan müzakereler 2007 yılı başında tekrar ivme kazanmış, özellikle tarım ve tarım-dışı ürünlerde pazara giriş müzakerelerinde ilerleme sağlanarak, indirim taahhütlerine ilişkin taslak hükümler 2008 yılı itibarıyla büyük ölçüde ortaya konulmuştur. Ancak, 2008 y1lı sonu itibariyle, yaşanan küresel ekonomik ve finansal kriz ile bağlantılı olarak farklı bir sürece girilmiş olup; müzakere tekniklerinin belirlenmesine yönelik sorunlu alanların aşılması hususunda somut bir ilerleme sağlanamamıştır.

2011'de Cenevre'de; 2013'te Bali'de yapılan Bakanlar Konferansı toplantılarının ardından kabul edilmiş kararlara bakıldığında, tarım başlığı altında, genel hizmetler, gıda güvenliği amaçlı kamu stok programları, ihracatta rekabet ve tarım ürünlerinde tarife kota yönetimi konularına ağırlık verildiği görülmektedir.

Gelinen aşama itibarı ile Doha müzakerelerinde, üye ülkeler arasında anlaşmazlık yaratan başlıca konuların iç destekler ayağında "de minimis" oranları, pazara giriş ayağında ise "tarife indirim 
yöntemi” olduğu görülmektedir. Müzakerelerin diğer bir ayağı olan ihracat rekabeti ise diğer iki alana kıyasla görece olgunlaşmış bir alan olarak kabul edilmektedir. Bu bağlamda Türkiye ile ilgili olarak ülkelerin en çok üzerinde durulan ve eleştirilen konuların başında tarife uygulamaları ile tarım ticareti gelmektedir.

Yukarıda açıklanan tüm bu süreçler boyunca da DTÖ kararlarının etkisiyle de hem küresel ticaret hem de tarımsal ticaret serbestleşmeye devam etmektedir. 1980 yılında 2 trilyon \$ seviyesinde olan toplam küresel ihracat hacmi, 2017 sonunda 17,7 trilyon \$'1 aşmıştır. Bu dönemde ortalama y1llık ihracat artış hızı \%5,1'in üzerinde olmuştur. Bununla birlikte, özellikle küresel krizin de etkisiyle son on yılda dünya ticaretinin durgunluğa girdiği görülmektedir. 1980'lerden bu yana küresel gayri safi hâsıla ortalama artış oranının $(\% 3,9)$ üzerinde gerçekleșen küresel ticaretteki ortalama artış oranı $(\% 7,76)$, son dönemde azalarak büyümenin gerisinde kalmıştır (GİF, 2018). Söz konusu gelişmelere ek olarak 19 trilyon $\$$ olan toplam dünya dış ticareti (2014) içerisinde tarım kaynaklı ihracat (tarım, gida ve tekstil) 2,5 trilyon \$'ın üzerinde bir değere sahip olup, toplam küresel dış ticaret içinde \%15'e yakın bir paya sahiptir (TiM, 2016).

Konuya Türkiye açısından bakıldığında; 2002 yılında 36,1 Milyar \$ olan ihracatın 2018 itibariyle 167,9 Milyar \$'a yükselirken, aynı dönemde tarımsal ürünleri ihracatı ise 4,1 Milyar \$'dan \%356,5 oranında artışla 18,5 Milyar \$'a yükseldiği görülmektedir. İthalatın gelişimi incelendiğinde ise 2002 y1lında 51,6 Milyar \$ olan genel ithalatın 2018 itibariyle 223 Milyar \$'a, tarımsal ürünlerde ise 4 Milyar \$'dan 18,3 Milyar \$'a yükseldiği görülmektedir (Tablo 1).

Tablo 1: Türkiye'nin 2002-2018 Dönemi D1ş Ticaret Durumu (Milyar \$)

\begin{tabular}{|c|c|c|c|c|}
\hline \multirow{2}{*}{ Yllar } & \multicolumn{2}{|c|}{ Genel Diş Ticaret } & \multicolumn{2}{c|}{ Tarım Ürünleri Diş Ticareti } \\
\cline { 2 - 5 } & İhracat & İthalat & İhracat & İthalat \\
\hline $\mathbf{2 0 0 2}$ & 36,1 & 51,6 & 4,1 & 4,0 \\
\hline $\mathbf{2 0 0 3}$ & 47,3 & 69,3 & 5,3 & 5,3 \\
\hline $\mathbf{2 0 0 4}$ & 63,2 & 97,5 & 6,5 & 6,1 \\
\hline $\mathbf{2 0 0 5}$ & 73,5 & 116,8 & 8,3 & 6,5 \\
\hline $\mathbf{2 0 0 6}$ & 85,5 & 139,6 & 8,6 & 7,3 \\
\hline $\mathbf{2 0 0 7}$ & 107,3 & 170,1 & 9,8 & 9,8 \\
\hline $\mathbf{2 0 0 8}$ & 132,0 & 202,0 & 11,5 & 13,0 \\
\hline $\mathbf{2 0 0 9}$ & 102,1 & 140,9 & 11,2 & 9,6 \\
\hline $\mathbf{2 0 1 0}$ & 113,9 & 185,5 & 12,7 & 12,9 \\
\hline $\mathbf{2 0 1 1}$ & 134,9 & 240,8 & 15,3 & 17,6 \\
\hline $\mathbf{2 0 1 2}$ & 152,5 & 236,5 & 16,0 & 16,4 \\
\hline $\mathbf{2 0 1 3}$ & 151,8 & 251,7 & 17,7 & 16,9 \\
\hline $\mathbf{2 0 1 4}$ & 157,6 & 242,2 & 18,7 & 18,1 \\
\hline $\mathbf{2 0 1 5}$ & 143,8 & 207,2 & 17,4 & 16,1 \\
\hline $\mathbf{2 0 1 6}$ & 142,5 & 198,6 & 16,9 & 15,6 \\
\hline $\mathbf{2 0 1 7}$ & 157,0 & 233,8 & 17,6 & 18,3 \\
\hline $\mathbf{2 0 1 8}$ & 167,9 & 223,0 & 18,5 & 18,3 \\
\hline Değisisim (\%) & $\mathbf{3 6 5 , 7}$ & $\mathbf{3 3 2 , 6}$ & $\mathbf{3 5 6 , 5}$ & $\mathbf{3 5 6 , 9}$ \\
\hline
\end{tabular}

Kaynak: TÜíK, 2019

Türkiye'de tarım sektöründe yaşanan bu dışa açık ve ihracata dayalı büyüme sürecinde tarım sektöründe "endüstri-içi ticaret" in gittikçe ağırlıklı bir yap1 kazanması yapılacak rekabet çalışmalarında diğer bir unsur olarak karşımıza çıkmaktadır. Dış ticaretin birbirine benzer malların üretildiği sektörlerde yoğunlaşması, literatürde "Endüstri-içi Ticaret" olarak adlandırılırken, öte yandan, dış ticaretin farklı endüstriler arasında yoğunlaşması ise "Endüstriler-arası ticaret" olarak nitelendirilmektedir (Ulucan ve ark., 2014). 
Balassa'nın (1966) yapmış olduğu çalışma endüstri içi ticaretin ölçümlenmesinde öncü rol üstlenmiş ve günümüzde yapılan çalışmalarda sıklıkla kullanılan Grubel-Lloyd (1975) endeksinin oluşmasında önemli rol oynamıştır. Endüstriler Arası Ticaret (EAT) ve Endüstri İçi Ticaretin (EIT) ölçümünde çok farklı yöntemler kullanılmaktadır. Bu yöntemler: Glubel Lloyd yaklaşımı, Düzeltilmiş Glubel Lloyd yaklaşımı, iki yönlü ticaret yöntemleri ile, Aguino, Balassa, Glejser Endeksi, GreenwayMilner endekslerdir. Endüstri-içi ticaretin ölçümlenmesinde kullanılan geleneksel endeksler olarak Balassa ve Grubel-Lloyd endeksleri öne çıkmaktadır (Türkeokul ve Abay, 2014).

Literatürde yer alan çalışmalar incelendiğinde bu yöntemin daha çok endüstri, madencilik, hizmetler alanında kullanıldığı görülmesine rağmen, son yıllarda tarım ve özellikle gıda, işlenmiş tarım ürünleri dış ticaretinin rekabet ölçümünde de kullanılmaya başlandığı görülmektedir.

(Bashimov ve ark. (2017) tarafından, 2001-2015 dönemi için yapılan çalışmada Açıklanmış Karşılaştırmalı Üstünlükler İndeksi, Açıklanmış Simetrik Karşılaştırmalı Üstünlükler İndeksi, Net Ticaret İndeksi ve Grubel-Lloyd İndeksi yöntemleri kullanılmıştır. Türkiye'nin gıda sektöründeki rekabet gücü yüksek bulunmuş olup, kakao, yenilen çeşitli gıda müstahzarları, içecek ve tütün ürünlerinde endüstri-içi ticaret düzeyinin yüksek olduğu saptanmıştır.

Erün (2010) yaptığı çalışmasında Türkiye'nin AB ile olan gıda ve canlı hayvan dış ticaretinde endüstri-içi ticaretini analiz etmiştir. Araştırmada endüstri-içi ticaretin ölçümünde Grubel-Lloyd indeksi kullanılmıştır. Araştırma sonucunda Türkiye ile AB-15 ve AB-27 arasındaki gıda ve canlı hayvan dış ticaretinin daha çok dikey endüstri-içi ticaret biçiminde gerçekleştiğini tespit etmiştir.

Küçükahmetoğlu ve Aydın (2015) tarafından yapılan çalışmalarında endüstri-içi ticaret teorisi aracılığıyla Türkiye'nin ticari hizmetler endüstri-içi ticaretinin ülkeye özgü belirleyicilerini tespit etmek, ulaşılan bulguları ticari mallar endüstri-içi ticaretinin ülkeye özgü belirleyicileri ile karşılaştırması amaçlanmıştır. Çalışmada 2005 yılı itibariyle önerilen ülkeye özgü belirleyiciler kümesi içinde en önemli faktörlerin; talep yapılarının benzerliği, ekonomik entegrasyonlara katılım ve ticari işlem maliyetleri olduğunu ortaya koymuştur.

Ulucan ve ark. (2014) çalışmalarında Türkiye ile yakın ticari partnerleri arasındaki dış ticarete konu olan tarım, madencilik ve imalat sanayi sektörleri kapsamında 1990-2013 yılları arası dönemde gerçekleşen endüstri-içi ticaretin gelişimi, Grubel-Llyod Endeksi kullanılarak incelenmiştir.

Türkekul ve Abay (2014) tarafından yapılan çalışmada Endüstri-içi Ticaret Teorisini (EIT) kullanarak Türkiye'nin tarımsal dış ticaret yapısı analiz edilmiştir. Farklı tarım ve gıda ürün grupları için hesaplanan endeks değeri Türkiye ve ticaret partnerleri arasındaki endüstri içi ticaret düzeyi yüksek bulunmuştur. Bunun da Türkiye'nin tarım sektörünün bu piyasalarla yüksek entegrasyonu olduğunu ifade etmektedir.

Mangır ve Fidan (2017) yaptıkları çalışmada Türkiye'nin 1996-2016 dönemi tarım sektörünün endüstri içi dış ticaretinin analizinin yapılması amaçlanmıştır. Çalışma sonucu gıda sektöründe yüksek endüstri-içi seviyesi ortaya koymakta iken, hammadde tarım ürünlerinde düşük çıkmıştır.

Şahin (2015) çalışmasında ise Türkiye ve AB-15 ülkelerinin 1996-2013 dönemi için tarımsal gıda ürünleri sektörü analiz edilerek, endüstri-içi ticaret düzeyinin Grubel- Lloyd endeksi kullanılarak belirlenmesi amaçlanmıştır. Sonuç olarak, Türkiye'nin endüstri-içi ticaretinin düşük kaliteli dikey endüstri-içi ticaret şeklinde gerçekleştiği görülürken, $\mathrm{AB}-15$ ülkelerinde dikey endüstri-içi ticaretin yüksek olduğu görülmüştür.

Bu çalışmada, Türkiye'nin 1990-2018 dönemi tarım sektörünü başta olmak üzere, alt sektörlerden gida maddeleri, canlı hayvan ve gıda maddeleri, içkiler, tütün ve mamulleri, hayvansal ve bitkisel yağlar ve mamulleri ile tarımsal hammaddelerin endüstri içi dış ticaretinin analizinin GrubelLloyd Endeksi ile yapılması amaçlanmıştır. Bununla birlikte Türkiye tarımında EİT ölçülürken dış 
ticarete konu olan ana alt sektörlerin toplam tarım sektörü EİT'deki rolünün tespit edilmesi de çalışma amaçları arasında yer almaktadır.

\section{Materyal ve Yöntem}

Çalışmada kullanılan veriler TÜIK'den alınmış olup, Standart Uluslararası Ticaret sınıflamasına (SITC, Rev.3) bazında tarım sektörü ve alt sektörlerden gıda maddeleri, canlı hayvan ve gıda maddeleri, içkiler, tütün ve mamulleri, hayvansal ve bitkisel yağlar ve mamulleri ile tarımsal hammaddelere ait 1990-2018 dönemi yıllık ihracat ve ithalat rakamlarından oluşmaktadır.

Çalışmada rekabet gücü hesaplamalarında Grubel ve Lloyd'un (1975) geliştirdiği ve literatürde en çok kullanılan yaklaşımların başında gelen Gruber-Llyold endeksi yöntemi kullanılmıştır. Söz konusu endeks;

\section{EIT $=1-[|\mathbf{X i}-\mathbf{M i}| /(\mathbf{X i}+\mathbf{M i})]$ $0 \leq$ EIT $\leq 1$}

$\mathbf{X i}=$ i malının veya endüstrinin ihracatı ve $\mathbf{M i}=\mathrm{i}$ malının veya endüstrinin ithalatı ifade etmektedir. Endeks değeri (EİT);

$>\mathbf{E I T}=\mathbf{0}$ olduğunda ülke ticaretinde o mal grubunda endüstri içi ticaretin olmadığ grubunda yalnız ihracat ya da ithalat yapıldı $\breve{g}$,

$>\mathbf{E I} \mathbf{T}=1$ olduğunda ülke ticaretinde o mal grubunda yapılan ihracat ve ithalatın değerlerinin birbirine yakın olduğu,

$>\mathbf{E I T}>\mathbf{0 , 5 0}$ olduğunda endüstri içi ticaretin yüksek olduğu,

$>\mathbf{E I T}<\mathbf{0 , 5 0}$ olduğunda endüstri içi ticaretin düşük olduğu anlaşılmaktadır.

Çalışmada yer alan çizelgeler ve veriler bu değerlendirmeye göre yapılmış olup, tablolarda endüstri içi ticaretin yüksek olduğu durumlar eity, düşük olduğu durumlar ise eitd, sembolleri ile gösterilmiştir.

\section{Endüstri İçi Ticaret Analizi Sonuçları}

Türkiye toplam tarımsal dış ticaretinde 1990-2018 dönemini kapsayan 28 yıllık dönemde endüstri içi ticaret değeri ortalamas1 0,92 iken, 1990-1999 döneminde 0,88, 2000-2009 döneminde 0,94 ve 2010-2018 döneminde 0,96 olarak hesaplanmıştır. Makro düzeyde oldukça yüksek olan EİT değerinin yıllar itibariyle gelişimi incelendiğinde ise en düşük EİT 1991 yılına ait olup değeri 0,70 olup, bunu sirasıyla 0,72 ve 0,79 ile 1994 ve 2014 yılları izlemektedir. Aynı EİT değeri dönemde gida maddelerinde 0,72 , canlı hayvanlar ve gida maddelerinde 0,56 , içkiler ve tütün mamullerinde 0,70 , hayvansal ve bitkisel yağlar ile mamullerinde 0,61 ve tarımsal hammaddelerde ise 0,33 olarak tespit edilmiştir. Ulucan ve ark. (2014) tarafından yapılan bir çalışmada, Türkiye'nin gelişmiş ülke ve ülke grupları ile dış ticaretinin, büyük ölçüde endüstri-içi ticarete dayalı olduğu tespit edilmiştir. $\mathrm{Bu}$ durumun ortaya çıkmasında, Türkiye'nin dış rekabet gücünü etkilemesi açısından, gümrük birliğinin etkisi önemli bir unsur olarak görülmüş̧ür. Ayrıca, Türkiye'de yaşanan 1994 ve 2001 krizleri ve ardından 2008 küresel krizlerin sonrası dönemlerinin hepsinde, gelişmiş ülke ve ülke grupları ile yapılan endüstri-içi ticaret endeksi değerinin düşme yönünde eğilim göstermesi belirlenmiştir. Söz konusu bu gelişmeler tarım sektörünü de doğrudan etkilemektedir.

Bu bağlamda sektör düzeyinde yüksek düzeylerde seyreden EİT değeri alt sektörlerde bazında incelendiğinde ise gıda maddelerinde de yüksek iken tarımsal hammaddelerde düşmektedir. Ayrıca gıda maddelerinde yüksek seyreden EİT değerleri alt sektörlerde azalma göstermektedir. Bu bağlamda 
süt, süt ürünleri ve yumurtalar, hububat, hububat ürünleri, kahve, çay, kakao, baharat ve ürünleri ile çeşitli yenilebilir ürünler (yağ, homojenize ürünler, sos, maya vb.) alt sektörlerinde endüstri içi ticaretin yüksek düzeyde gerçekleşirken, diğer yandan canlı hayvanlar, et ve et ürünleri, balıklar ve diğer deniz ürünleri, meyve ve sebzeler, şeker, şeker ürünleri ve bal, hayvanlar için gida maddeleri, içkiler, hayvansal sıvı ve katı yağlar, bitkisel sıvı yağlar ve franksiyonları, yağlı tohumlar, yağ veren meyveler ile işlenmemiş kösele, deri ve kürk, ham kauçuk, mantar, odun ve kereste, kağıt hamuru ve kullanılmış kağıt ve dokuma elyafı ve bunların artıklarından oluşan tarımsal hammaddelerde endüstri içi ticaretin düşük düzeyde gerçekleştiği görülmektedir (Grafik 1).

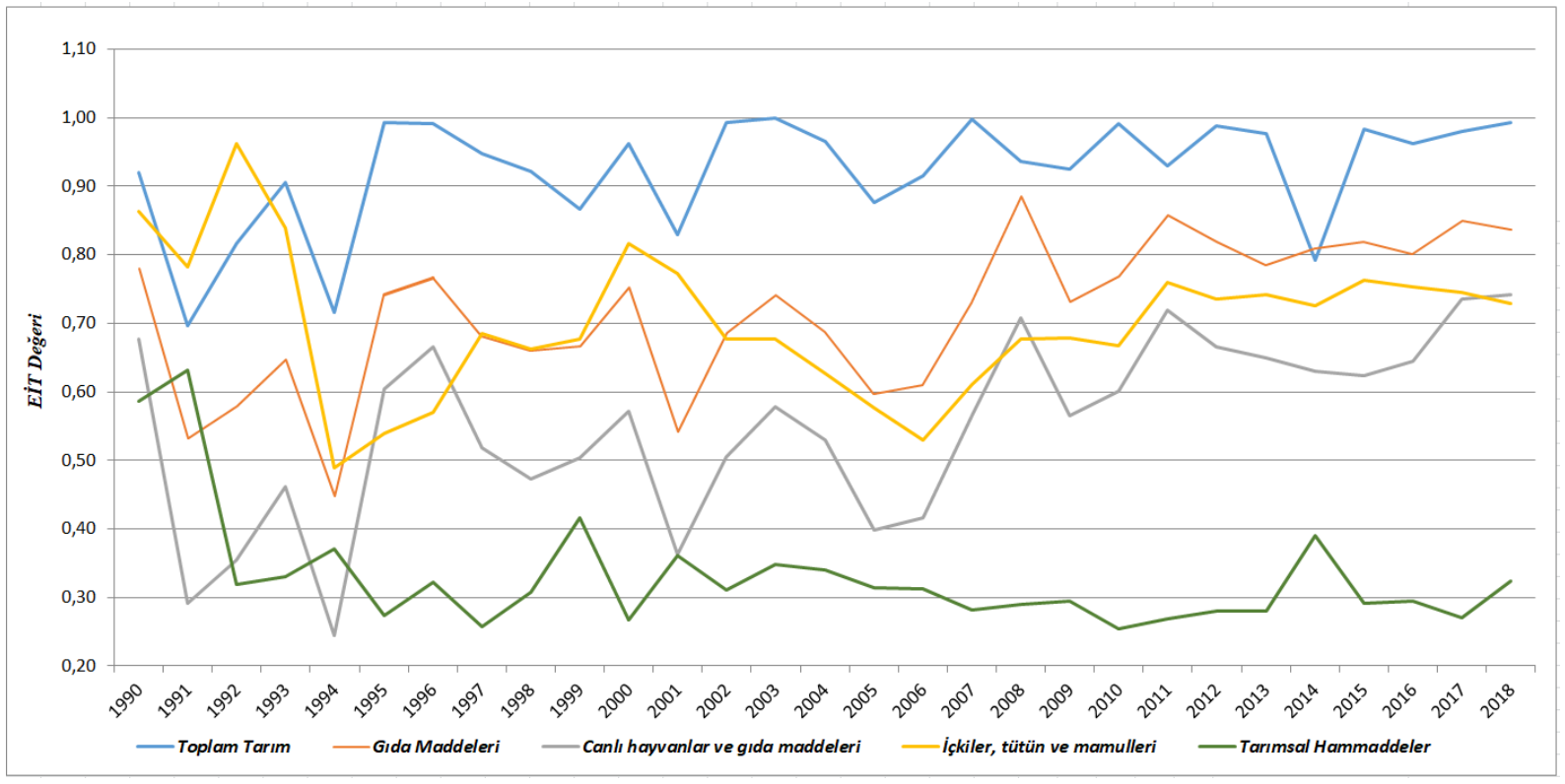

Grafik 1: Türkiye'nin Tarımsal Ürünlerde Endüstri İçi Ticaret Değeri

EITT değeri tüm yıllar için gıda maddelerinde en düşük değeri 1994 yılında 0,45 iken en yüksek 2008 yılında 0,89 olarak hesaplanmıştır. Diğer yıllara ait değerler, bu iki değer arasında gerçekleşip, ortalaması 0,72 'dir. Toplam tarımsal ürünlerin dış ticaretine göre karşılaştırma yapıldığında ise, ortalamanın altında görünse de yine de yüksek hesaplanmıştır. Bununla birlikte EİT değerinin yıllar itibariyle gelişimine bakıldığında ise gıda maddelerinde 1990'da 0,78 olan bu değer 2018 yılında 0,84'e; canlı hayvanlar ve gida maddelerinde 1990'da 0,68 olan değerin 2018 yılında 0,74'e, hayvansal ve bitkisel yağlarda 1990'da 0,63 olan EİT değerin 2018 y1lında 0,84'e yükseldiği görülmektedir. Diğer bir deyişle bu sektörlerde söz konusu dönemde ithalatın da ağırlığının arttığı görülmektedir. Diğer yandan içkiler ve tütün mamullerinde 1990'da 0,86 olan EİT değerinin 2018 y1lında 0,73 'e ve tarımsal hammaddelerde ise 1990 'da 0,59 olan değerin 2018 yılında 0,32 'ye düştüğü belirlenmiştir (Çizelge 1).

Gıdada alt sektörlerden birisi olan canlı hayvanlar ve gida maddeleri ticaretinde bazı dönemlerde EİT'nin düşük bazı dönemlerde yüksek olduğu gözükmesine karşın, 2017 ve 2018 y1llarında 0,65'in üzerinde gerçekleştiği görülmektedir. Bu gruba ait en düşük değer 0,24 ile 1994 y1lına aitken 0,74 değeri ile 2018 yılına aittir.

Bununla birlikte diğer bir alt sektör olan içkiler, tütün ve mamullerinde EİT, çok yüksek olmamak ile birlikte inceleme dönemi boyunca dalgalanma gösterdiği görülmektedir. Diğer bir alan olan hayvansal, bitkisel katı ve siv1 yağlar, mumlar kalemi incelendiğinde 2000, 2002, 2008, 2010 ve 2015 yıllarında EITT düşük iken diğer yıllarda (23 yıl) EİT'nin yüksek olduğu tespit edilmiştir. Ayrıca 
özellikle 2015 yılında bu değerin 0'a yakın olması da önemli bir gelişme olarak değerlendirilmektedir. Tarımsal hammaddelere sonuçlar incelendiğinde ise bütün yıllarda EİT'nin düşük olduğu, en düşük değer 0,25 (1997 ve 2010) iken en yüksek değer 0,63 (1991) olup tüm y1llar genel ortalamas1 0,33'tür.

Çizelge 1: Türkiye'de 1990-2018 Dönemi Tarımsal Ürünlerde Endüstri İçi Ticaret Değeri

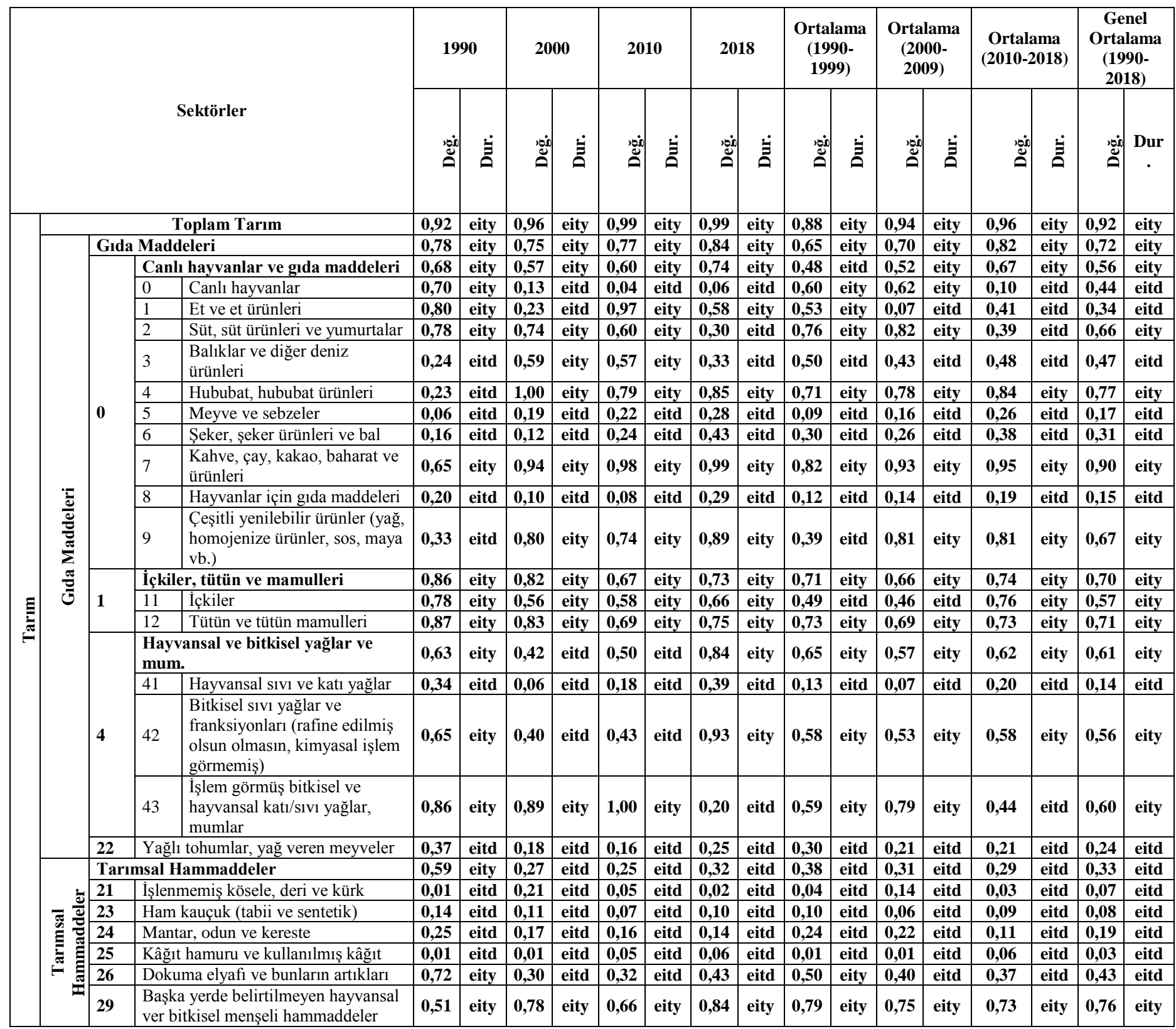

Kaynak: Yazar Hesaplamaları

\section{Sonuç ve Öneriler}

Türkiye toplam tarımsal diş ticaretinde 1990-2018 dönemini kapsayan 28 yıllık dönemde endüstri içi ticaret değeri ortalaması 0,92 olup, makro düzeyde oldukça yüksek olan EİT değeri gıda maddelerinde 0,72 olarak tespit edilmiştir. Bu durumun Türkiye'nin tarım ve gıda ürünleri dış

\section{Turkish Studies - Social Sciences}

Volume 14 Issue 4, 2019 
ticaretinde yüksek endüstri-içi ticaret avantajına sahip ve potansiyeli bulunmasına karşın, dış ticarette uygulanan koruma oranları ile ilişkili olduğu söylenebilir. Başka bir ifade ile Türkiye'nin tarım ve işlenmiş tarım ürünleri ticaretinde hem ihracatçı hem de ithalatçı konumda olduğu ve bunda da koruma önlemlerinin etkili olduğu görülmektedir. Ayrıca $\mathrm{AB}$ ile yürütülen Gümrük Birliği'nin güncellenmesi sürecinde tarım sektörünün de kapsama alınması ve serbestleşme çeşitli ürünlerde önemli rekabet baskısı oluşturabilecektir. Bu bağlamda Türkiye'nin tarım ve doğal kaynaklarının etkin ve verimli kullanılması, girdi maliyetlerinin azaltılması, tüketici fiyatlarının düşürülmesi rekabet gücünü arttıracak önlemeler arasında sayılabilir. Sonuç olarak Türkiye, tarımda liberalleşme sürecinde yeni koşullara göre oluşacak rekabet ortamına uyum amacıyla yeni politika ve strateji geliştirmesi gerekmektedir.

Diğer yandan, oluşturulacak yeni politika ve stratejilerde uluslararası kurum ve kuruluşlara karşı taahhütlerin dikkate alınması gerekmektedir. Bu kapsamda DTÖ'nde dile getirilen eleştirilerin önemli bir bölümünü, tarım ürünlerinde koruma oranlarının yüksekliği, tarımsal destek politikalarında DTÖ yükümlülüklerinin dikkate alınmaması, bildiririm yükümlülüğünün yerine getirilmemesi ve ihracat sübvansiyonları oluşturmaktadır.

Sonuç olarak küresel piyasalarda yaşanmakta olan süreçler, yaşanan döviz krizi ile başlayan ve gıda fiyatlarının artışı ile devam eden süreçte Türkiye'de tarım ve gıda sektörünün yeni politikalara ihtiyacı olduğunu ortaya koymaktadır. Bu bağlamda rekabette var olan karşılaştırmalı avantajın korunması ve rekabet gücünün arttırılması amacıyla maliyetlerin azaltılması, yerel ve coğrafi işaret gibi araçlarla da markalaşmanın arttırılması, kayıtdışı ile mücadele, dış ticarette pazar çeşitlendirmesi, katma değeri yüksek ürünlerin üretilmesi ve dijital tarıma geçiş süreçlerine yatırım yapılmasına bağlidır.

\section{KAYNAKÇA}

Altay H., Şen A. 2009. Türkiye'nin Avrupa Birliği (15) Pazarındaki Endüstri-İçi Ticaret Performansının Rakip Ülke Performanslarıyla Karşılaştırmalı Analizi:1995-2007, Dumlupınar Üniversitesi, Sosyal Bilimler Dergisi, Say1:25, Sivas.

Bashimov G., Çiçek R., Aydın A. 2017. Türk Gıda Sanayiinin Dış Ticaret Yapısının Analizi. Giresun Üniversitesi, İktisadi ve İdari Bilimler Dergisi, ISSN: 2149-3391, Y11: 3 Say1: 5, Giresun.

Erün G. 2010. Türkiye ile AB, Gıda ve Canlı Hayvan Sektörü Dış Ticaretinde Endüstri-İçi Ticaret Analizi. Ekonomi Bilimleri Dergisi, 2(1), 71-78.

Eşiyok B.A. 2015. Tarımsal Ürünlerde Türkiye-AB Arasında Dış Ticaretin Analizi, Endüstri-İçi Ticaret ve Rekabet Gücü. Türkiye Kalkınma Bankası A.Ş., ISBN 975-7406-49 -X / 7406$69-4$.

GIF, 2018. Küresel Ticarette Dönüşüm ve Türkiye. Global İlişkiler Forumu Çalışma Grubu Raporu, ISBN: 978-605-83113-7-4, Global İlişkiler Forumu, İstanbul.

Küçükahmetoğlu O., Aydın A. 2015. Intra-Industry Trade in Commercial Services of Turkey: An Empirical Study for the Identification of Country-Specific Determinants. Yönetim ve Ekonomi Araştırmaları Dergisi-Cilt:13 Sayı:1.

Mangır F., Fidan A. 2017. Grubel-Lloyd Endeksi ile Endüstri-İ̉i Ticaret Analizi: Tarım Sektörü Türkiye Örneği. KMÜ Sosyal ve Ekonomik Araştırmalar Dergisi 19 (33): 45-51, 2017 ISSN: 2147-7833. 
Şahin D. 2015. Türkiye'nin Tarımsal Gıda Ürünlerinin Endüstri-İci Ticaretinin Analizi: AB-15 Ülkeleri ile Karşılaştırmalı Analiz. Uluslararası Hakemli Ekonomi Yönetimi Araştırmaları Dergisi, Nisan / Mayıs / Haziran - İlkbahar Yaz Dönemi Sayı: 4.

TİM, 2016. Tarım Raporu. Türkiye İhracatçılar Meclisi, Dış Ticaret Kompleksi Çobançeşme Mevkii, Sanayi Cad. B Blok Kat:9 (34196) Yenibosna-İstanbul.

TÜİK, 2019. Türkiye İstatistik Kurumu (Erişim Tarihi: 17.06.2019).

Türkekul B., Abay., C, 2014. Dünya Tarım Ürünleri Piyasalarının Değişen Dinamikleri ve Türkiye'nin Rekabet Gücü. XI. Ulusal Tarım Ekonomisi Kongresi 3-5 Eylül 2014, Samsun.

Ulucan H., Çeviş İ., Ceylan R. 2014. “Türkiye'de Endüstri-İçi Ticaretin Gelişimi”, E-Journal of New World Sciences Academy, NWSA-Social Sciences, ISSN: 1306-3111/1308-7444. 